УДК $338.48,332.142 .4$

JEL R12; Z32

$10.17213 / 2075-2067-2019-4-77-83$

\title{
ПРОЕКТИРОВАНИЕ ПРОСТРАНСТВЕННОЙ ОРГАНИЗАЦИИ РЕКРЕАЦИОННОЙ СИСТЕМЫ ПРИГРАНИЧНОГО РЕГИОНА ${ }^{1}$
}

\author{
(C) 2019 г. А. В. Васильева
}

\section{Институт экономики Карельского научного центра РАН, г. Петрозаводск}

Важно подходить к планированию пространственной организации комплексно $и$ системно. В современных экономических подходах принято отказываться от идеи саморегулирующего рынка. Не всегда элементы экономической системы возникают там, где это эффективно. Это характерно и для рекреации как вида экономической деятельности.

В работе представлен механизм проектирования пространственной организачии рекреационной системы приграничного региона, который включает в себя три этапа: оценка современного состояния рекреационной системы приграничного региона; выявление наиболее перспективных направлений развития рекреационной деятельности; организаџия прочесса планирования пространственной организации рекреационной системы приграничного региона. Для последовательной проработки этих содержательных этапов предложен инструментарий, который позволяет учесть локальные особенности в прочессе согласования действий на федеральном, региональном и муниципальном уровнях. Такой подход расширяет возможности применения в практической области для решения социально-экономических проблем приграничных регионов.

Ключевые слова: пространственное развитие; приграничный регион; рекреаџионная система.

It is important to plan the spatial organization in an integrated and systematic way. In modern economic approaches, it is customary to abandon the idea of a self-regulatory market. Elements of the economic system do not always arise where it would be most effective. This is also characteristic of recreation as a type of economic activity.

The design mechanism of the spatial organization of the recreational system of the border region, which includes three stages is presented in the work: assessment of the current state of the recreational system of the border region; identification of the most promising areas for the development of recreational activities; organization of the planning process for the spatial organization of the recreational system of the border region. For a consistent study of these substantive stages, a toolkit has been proposed that allows taking into account local features in the process of coordinating actions at the federal, regional and municipal levels. This approach expands the possibilities of applying this mechanism in the practical field to solve the socio-economic problems of border regions.

Key words: spatial development; border region; recreational system.

1 Исследование выполнено в рамках государственного задания КарНЦ РАН «Институты и социальное неравенство в условиях глобальных вызовов и региональных ограничений» (0218-2019-0090). 


\section{Введение}

Любые планы и стратегии развития реализуются в экономическом пространстве. Концепции социально-экономического развития необходимо проецировать на конкретное геоэкономическое пространство. Территория становится местом реализации планов и задумок. Расстояния и инфраструктурная обеспеченность вносят определенные коррективы в способы ведения хозяйственной деятельности страны и ее регионов. При этом концепция пространственного развития должна отражать интересы всех заинтересованных сторон на всех уровнях (от уровня домохозяйств до уровня геополитических интересов страны).

Социально-экономическая система страны в пространственном аспекте и механизмы регулирования пространственного социально-экономического развития изучаются географами и экономистами $[1,2,3$, $5,6]$. Понятие пространства в региональной экономике является одним из базовых. В общем смысле понятие экономического пространства связано с существованием неких географических рамок существования экономической системы.

В рамках новой экономической географии экономическое пространство определяется такими характеристиками, как плотность, расстояние и разобщенность. Посредством этих характеристик можно понять степень доступности регионального рынка.

При этом основные особенности экономического развития регионов связаны с пространственной неравномерностью. Как правило, на разных уровнях (региональном и национальном) наблюдаются различные масштабы неравномерности, то есть в рамках страны степень неравномерности экономического развития ее регионов менее масштабна, чем различия в экономическом развитии стран. Возможность получать выгоды от растущей экономической концентрации стала основной тенденцией в пространственной организации экономических систем. На практике это проявляется в урабанизационных процесcax, увеличении доли городского населения, разрастании мегаполисов как центров экономической активности и социальной среды. Дополнительный эффект от процесса разрастания мегаполисов - это «перелив» эконо- мической активности и на другие сопредельные территории.

\section{Методика исследования}

Одна из наиболее важных проблем в современном геоэкономическом развитии - увеличивающиеся масштабы неравномерности уровня жизни в разных регионах. На решение этой проблемы и на поиск механизмов сглаживания разницы базовых показателей в самых развитых и самых отстающих регионах направлены усилия ученых экономистов $[4,7,8]$. Многочисленные исследования показывают, что нельзя ожидать равномерного экономического развития и роста. Однако по всему миру страны стремятся внедрять политику выравнивания.

Для российских регионов также характерна выраженная неравномерность экономического развития. В связи со спецификой неравномерности и расселения, и инфраструктуры вопрос пространственной организации можно считать одним из наиболее актуальных для российской практики регионального развития. Развитие национальной рекреационной системы рассматривается как возможность для сглаживания неравномерности развития, повышения качества человеческого капитала, инициирования создания рабочих мест благодаря относительно высокой трудоемкости данной сферы деятельности и привлечению инвестиций в инфраструктурные объекты. При этом высокий рекреационный потенциал территории не гарантирует успешное развитие туризма и проявление соответствующих позитивных социальных и экономических эффектов. Оптимальная пространственная организация - необходимое условие эффективного и устойчивого использования рекреационных ресурсов и их комплексного неистощительного использования. Таким образом, пространственная организация территориальных рекреационных систем связана не только с попытками достижения экономическими целей, но и с экологическими и социальными аспектами, соблюдением научно обоснованных нормативов воздействия.

В работе представлен механизм проектирования пространственной организации рекреационной системы региона, который включает в себя три этапа. 


\section{Результаты и выводы}

Важно подходить к пространственной организации комплексно и системно. Не всегда элементы экономической системы возникают там, где это было бы эффективно. Наиболее актуально это для инфраструктурных объектов. Это характерно и для рекреационной деятельности как вида экономической. В связи с этим необходима поэтапная проработка процесса проектирования рекреационной системы.

На первом этапе автором предлагается осуществление комплексной оценки рекреационной системы приграничного региона. Эта процедура включает в себя четыре смысловых блока, направленных на наиболее полный охват всех возможных характеристик (табл. 1). Так, на этом этапе предполагается оценка количества и качества рекреационных ресурсов (природных, природно-антропогенных, антропогенных, социально-истори- ческих) и рекреационной инфраструктуры. При этом к этой инфраструктуре автор относит туристические компании, гостиничные предприятия, предприятия питания, транспортные организации и другие учреждения, предоставляющие рекреационные и сопутствующие услуги. Инвентаризация инфраструктурных элементов помогает выявить потребности местного населения и рекреантов. Определение функциональных и пространственных принципов размещения инфраструктуры помогает оптимизировать рекреационные нагрузки.

Приграничное положение оказывает влияние не только на формирование специальной инфраструктуры, направленной на прохождение туристских потоков, но и создает особые режимы, выводящие значительные территории из рекреационной и хозяйственной деятельности. Таким образом, с одной

Таблица 1

\section{I Этап: Оценка современного состояния рекреационной системы приграничного региона}

\begin{tabular}{|c|c|}
\hline Смысловые блоки этапа & Содержание смысловых блоков \\
\hline $\begin{array}{l}\text { 1. Инвентаризация } \\
\text { рекреационных } \\
\text { ресурсов }\end{array}$ & $\begin{array}{l}\text { — природные ресурсы, условия и явления (ландшафт, водные ре- } \\
\text { сурсы, растительный покров); } \\
\text { - природно-антропогенные (охотничьи угодья, особо охраняе- } \\
\text { мые природные территории); } \\
\text { - антропогенные (аквапарки, стадионы, музеи, банно-саунные } \\
\text { комплексы); } \\
\text { - социально-исторические (культурные объекты, памятники, ис- } \\
\text { торические местности). }\end{array}$ \\
\hline $\begin{array}{l}\text { 2. Инвентаризация } \\
\text { рекреационной } \\
\text { инфраструктуры }\end{array}$ & $\begin{array}{l}\text { - инвентаризация туристских фирм и гостиничных предпри- } \\
\text { ятий и предприятий питания в проекции на географическое про- } \\
\text { странство; } \\
\text { — оценка транспортной обеспеченности; } \\
\text { - оценка существующей обслуживающей инфраструктуры; } \\
\text { — инвентаризация других учреждений, предоставляющих рекре- } \\
\text { ационные и другие сопутствующие услуги. }\end{array}$ \\
\hline $\begin{array}{l}\text { 3. Анализ } \\
\text { рекреационной } \\
\text { деятельности в регионе }\end{array}$ & $\begin{array}{l}\text { — анализ и оценка динамики туристских потоков; } \\
\text { — определение баланса туристских потоков; } \\
\text { — мониторинг развития туризма по основным показателям; } \\
\text { — налоговые поступления от субъектов туристского бизнеса. }\end{array}$ \\
\hline $\begin{array}{l}\text { 4. Определение потреб- } \\
\text { ностей в инфраструктур- } \\
\text { ном обеспечении (с уче- } \\
\text { том предыдущих этапов) }\end{array}$ & $\begin{array}{l}\text { - определение функциональных и пространственных зависи- } \\
\text { мостей при размещении рекреационной инфраструктуры; } \\
\text { - определение потребностей в рекреационной инфраструктуре; } \\
\text { - определение потребностей в развитии приграничной инфра- } \\
\text { структуры. }\end{array}$ \\
\hline
\end{tabular}


стороны проявляется барьерная и контактная функция границы одновременно, с другой стороны барьерная функция долгие годы способствовала сохранению природных ресурсов. Эти ресурсы приграничных территорий могут стать площадкой для разработки и внедрения социальных, гуманитарных и экологических проектов и технологий, основанных на многолетнем опыте международного сотрудничества в области реализации совместных международных междисциплинарных проектов.

Результаты первого этапа становятся основой для второго этапа, целью которого является выявление наиболее перспективных направлений развития рекреационной деятельности (табл. 2). Этот процесс предполагает осуществление оценки локализующих факторов формирования приграничной рекреационной системы. К таким факторам относят геополитические, экономические, экологические, институциональные, социальные, этнографические, управленческие факторы, факторы приграничного положения и инновационного развития.

Целесообразно на этом этапе определить общие задачи развития рекреационной системы. Эти задачи дополняются задачами целевого характера, например, для расширения предложения на рынке рекреационных услуг необходимо обеспечить доступ к рекреационным объектам или для использования опыта приграничной Финляндии в области развития рекреационной деятельности на ООПТ необходимо выстраивать трансграничные партнерские сети заинтересованных сторон, при этом задачи целевого характера должны корреспондироваться общими задачами.

\section{II Этап: Выявление наиболее перспективных направлений развития рекреационной деятельности}

Таблица 2

\begin{tabular}{|c|c|}
\hline Смысловые блоки этапа & Содержание смысловых блоков \\
\hline $\begin{array}{l}\text { 1. Определение и оценка } \\
\text { локализующих факторов } \\
\text { формирования рекреаци- } \\
\text { онной системы пригра- } \\
\text { ничного региона }\end{array}$ & $\begin{array}{l}\text { - геополитические факторы; } \\
\text { - экономические факторы; } \\
\text { — экологические факторы (емкость, риски, пр.); } \\
\text { - институциональные факторы; } \\
\text { — факторы приграничного положения; } \\
\text { — факторы инновационного развития; } \\
\text { — социальные факторы; } \\
\text { - этнографические факторы; } \\
\text { - управленческие факторы. }\end{array}$ \\
\hline $\begin{array}{l}\text { 2. Определение общих } \\
\text { задач развития рекреаци- } \\
\text { онной деятельности }\end{array}$ & $\begin{array}{l}\text { — расширение предложения на рынке рекреационных услуг; } \\
\text { — разработка совместных трансграничных маршрутов с исполь- } \\
\text { зованием рекреационных ресурсов приграничных территорий; } \\
\text { - разнообразие ценового диапазона; } \\
\text { — информационное продвижение; } \\
\text { — использование потенцила приграничного положения. }\end{array}$ \\
\hline $\begin{array}{l}\text { 3. Определение задач } \\
\text { целевого характера } \\
\text { (в соответствии с общи- } \\
\text { ми задачами) }\end{array}$ & $\begin{array}{l}\text { - обеспечение доступа к рекреационным объектам; } \\
\text { - выстраивание функциональных взаимосвязей рекреационной } \\
\text { системы с другими региональными территориальными системами; } \\
\text { - развитие инфраструктуры для управления потоками посетите- } \\
\text { лей и антропогенными нагрузками на объекты. }\end{array}$ \\
\hline $\begin{array}{l}\text { 4. Определение сфер для } \\
\text { инновационного разви- } \\
\text { тия региональной рекре- } \\
\text { ационной системы }\end{array}$ & $\begin{array}{l}\text { — создание новых продуктов (в том числе трансграничных); } \\
\text { — внедрение новых организационно-управленческих техноло- } \\
\text { гий и технологических решений; } \\
\text { — освоение новых рынков рекреационных услуг; } \\
\text { — применение новых финансовых инструментов развития. }\end{array}$ \\
\hline
\end{tabular}


III Этап: Организация процесса планирования пространственной организации рекреационной системы приграничного региона

\begin{tabular}{|c|c|}
\hline Смысловые блоки этапа & Содержание смысловых блоков \\
\hline $\begin{array}{l}\text { 1. Отражение целей раз- } \\
\text { вития рекреационной } \\
\text { деятельности в действу- } \\
\text { ющих документах пла- } \\
\text { нирования }\end{array}$ & $\begin{array}{l}\text { - Стратегия социально-экономического развития РФ, Стратегия } \\
\text { пространственного развития РФ, отраслевые документы страте- } \\
\text { гического планирования РФ (Стратегия развития культуры РФ), } \\
\text { ГП РФ «Развитие культуры и туризма» на 2013-2020 годы, ФЦП } \\
\text { «Развитие внутреннего и въездного туризма в Российской Феде- } \\
\text { рации (2011-2018 годы)» и пр. (федеральный уровень); } \\
\text { - стратегия социально-экономического развития субъекта РФ, } \\
\text { схема территориального планирования субъекта, отраслевые до- } \\
\text { кументы развития субъектов РФ и пр. (региональный уровень); } \\
\text { - стратегия социально-экономического развития муниципаль- } \\
\text { ного образования, муниципальная программа и пр. (муниципаль- } \\
\text { ный уровень); } \\
\text { - проверка на согласованность целей развития в документах } \\
\text { всех уровней. }\end{array}$ \\
\hline $\begin{array}{l}\text { 2. Оценка институцио- } \\
\text { нальной среды разви- } \\
\text { тия рекреационной де- } \\
\text { ятельности }\end{array}$ & $\begin{array}{l}\text { - федеральные законы, правовые акты Президента РФ и Прави- } \\
\text { тельства РФ, правовые акты органов исп. власти и пр. (федераль- } \\
\text { ный уровень); } \\
\text { - региональные целевые программы развития туризма, гене- } \\
\text { ральные схемы размещения объектов инфраструктуры (в том чис- } \\
\text { ле и туристской) и пр. (региональный уровень); } \\
\text { - планы мероприятий (дорожные карты) по развитию рекреаци- } \\
\text { онной деятельности, соглашения о муниципально-частном парт- } \\
\text { нерстве (в области развития рекреационной деятельности), планы } \\
\text { мероприятий (дорожные карты) по развитию рекреационной де- } \\
\text { ятельности и пр. (муниципальный уровень). }\end{array}$ \\
\hline $\begin{array}{l}\text { 3. Определение и } \\
\text { ранжирование барьеров } \\
\text { развития }\end{array}$ & $\begin{array}{l}\text { - барьеры со стороны государства; } \\
\text { — кадровые проблемы; } \\
\text { - финансирование; } \\
\text { - оценка спроса; } \\
\text { - инфраструктурные проблемы; } \\
\text { - информационное продвижение; } \\
\text { - отсутствие инвестиционных площадок, обеспеченных необхо- } \\
\text { димой инженерной и транспортной инфраструктурой. }\end{array}$ \\
\hline $\begin{array}{ll}\text { 4. Разработка схемы раз- } \\
\text { вития рекреационной } \\
\text { деятельности с учетом } \\
\text { результатов } & \text { предыду- } \\
\text { щих этапов } & \end{array}$ & $\begin{array}{l}\text { - учет рекреационной емкости и потенциала инфраструктуры; } \\
\text { - разработка подходов проектного планирования и финансирования; } \\
\text { - определение и корректировка направлений пространственной } \\
\text { организации; } \\
\text { - комплексная оценка возможностей практического внедрения } \\
\text { разработанной схемы; } \\
\text { - встраивание в региональные программы и соответствие при- } \\
\text { оритетам инвестиционной политики в регионе; } \\
\text { - обеспечение информационной и маркетинговой поддержки } \\
\text { проектов, реализуемых в сфере туризма и рекреации. }\end{array}$ \\
\hline
\end{tabular}


Определение сфер инновационного развития поможет определить векторы для дальнейшей работы по повышению конкурентоспособности рекреационной системы приграничного региона.

На завершающем третьем этапе для проектирования пространственной организации рекреационной системы автор предлагает проработку четырех смысловых блоков (табл. 3). Во-первых, необходимо оценить институциональную среду для развития рекреационной деятельности. Она определяется факторами предыдущего этапа и формирует актуальное правовое поле, представленное федеральными законами, правовыми актами Президента и Правительства РФ и пр. на федеральном уровне. Региональный уровень представлен, как правило, генеральными схемами размещения объектов инфраструктуры и региональными целевыми программами развития туризма. Муниципалитеты применяют в своей практике такие институты, как планы мероприятий по развитию рекреационной деятельности, соглашения о муниципально-частном партнерстве и пр.

Следующий шаг предполагает определение целей развития рекреационной деятельности в действующих документах. Исходными данными на этом этапе становятся действующие стратегии социально-экономического развития, стратегии пространственного развития, отраслевые документы стратегического планирования федерального, регионального и муниципального уровней.

Здесь необходимо проверить взаимную согласованность целей, задач, мероприятий и индикаторов, выявить пробелы и дублирование. Содержательный анализ позволяет выявить основные проблемные области.

Дополнение этого анализа исследованием практического поля позволяет определить и ранжировать основные барьеры развития рекреационной деятельности. На основе всех предыдущих действий и с учетом их результатов разрабатывается схема развития рекреационной системы.

Предложенный инструментарий расширяет возможности для последовательной проработки этих содержательных этапов, позволяет учесть локальные особенности в процессе согласования действий на федеральном, региональном и муниципальном уровнях, может применяться в практической области для решения социально-экономических проблем регионов с учетом их приграничного положения.

\section{Литература}

1. Бакланов П.Я. Пространственное развитие региона: основные принципы и подходы к анализу и оценкам // Вестник АРГО. 2017 (6). - C. 4-11.

2. Бездудная А.Г., Разумовский В. М., Фраймович Д.Ю. Диагностика пространственных аспектов и факторов инновационного развития регионов. - Санкт-Петербург, 2018. - С. 217.

3. Гранберг А.Г. Программа фундаментальных исследований пространственного развития России и роль в ней Северо-Западного региона // Экономика Северо-Запада: проблемы и перспективы развития. 2009. 一 №1 (38). - C. 1-6.

4. Зубаревич Н. В. Социально-экономическое развитие регионов: итоги 2018 г. // Экономическое развитие России. - 2019. T. 26. - №3. - С. 52-55.

5. Зубаревич Н.В. Стратегия пространственного развития: приоритеты и инструменты // Вопросы экономики. — 2019. — №1 . C. $135-145$.

6. Пилясов А.Н. По гамбургскому счету (ответ на статью П. Я. Бакланова «продолжаем дискуссию») // Региональные исследования. - 2013. - №2 (40). - С. 125-134.

7. Римашевская Н.М., Мигранова Л.А. Социально-экономическое неравенство в России // Народонаселение. — 2016. — №3 (73). C. 17-33.

8. Скуфьина Т.П., Баранов С.В. Феномен неравномерности социально-экономического развития городов и районов Мурманской области: специфика, тенденции, прогноз, регулирование // Экономические и социальные перемены: факты, тенденции, прогноз. 2017. - T. 10. — №5. - C. 66-82. 


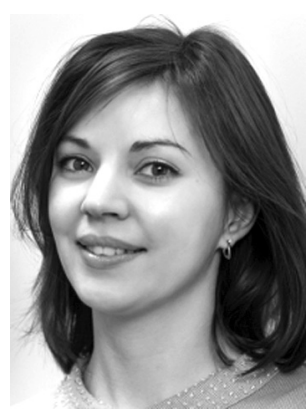

Васильева Анастасия Владимировна - младший научный сотрудник Института экономики Карельского научного центра Российской академии наук.

Vasilieva Anastasia Vladimirovna - Junior Research Associate of Institute of Economics of the Karelian Research Centre of the Russian Academy of Sciences.

185030 , г. Петрозаводск, пр. А. Невского, 50 50 A. Nevskogo av., 185030, Petrozavodsk, Russia Тел.: +7 (814) 257-15-25, факс: +7 (814) 257-07-27

E-mail:vasnask@gmail.com 